\title{
Construction of an Integrated Management System for Underground Pipelines in the Context of Holistic Governance
}

\author{
Wang Teng ${ }^{1, \mathrm{a}}, \mathrm{Xu}$ Dong $^{2, \mathrm{~b}}$, Du Xuan ${ }^{3, \mathrm{c}}$, Han Xiaosong ${ }^{4, \mathrm{~d}^{*}}$ \\ ${ }^{1}$ Beijing Institute of New Technology Application,Beijing, China \\ ${ }^{2}$ Beijing Institute of New Technology Application,Beijing, China \\ ${ }^{3}$ Beijing Institute of New Technology Application,Beijing, China \\ ${ }^{4}$ Beijing Institute of New Technology Application,Beijing, China \\ aholly_wagteng@163.com \\ ${ }^{b}$ xdong_ustb@yeah.net \\ ${ }^{c} n m g d x 001 @ 163 . c o m$ \\ $d^{*} x s o n g 0124 @ 163 . c o m$
}

\begin{abstract}
Underground pipelines assume the functions of energy transportation, resource supply, information transmission, etc., and are one of the most important infrastructure of the city, as well as an important public good. The government, as the main body of public product management and maintenance, uses holistic governance as the theoretical basis to build communication and coordination mechanisms, resource integration mechanisms, information sharing mechanisms, cooperative regulatory mechanisms and improve the comprehensive management system of underground pipelines, which is of great significance for maintaining urban safety, stability and sustainable development.
\end{abstract}

Keywords: Holistic Governance, Underground plPipeline, Integrated Management, Information Sharing

\section{整体性治理下地下管线综合管理体系建设}

王腾 ${ }^{1,}$ a 徐栋 ${ }^{2,}$ b 杜轩 ${ }^{3, \mathrm{c}}$ 韩晓松 ${ }^{4, d *}$

${ }^{1}$ 北京市新技术应用研究所, 北京, 中国

北京市新技术应用研究所, 北京, 中国

北京市新技术应用研究所, 北京, 中国

北京市新技术应用研究所, 北京, 中国

${ }^{a}$ holly_wagteng@163.com

${ }^{b}$ xdong_ustb@yeah.net

${ }^{c}$ nmgdx001@163.com

d*xsong0124@163.com

\section{摘要}

地下管线承担着能源运输、资源供给、信息传输等功能，是城市最主要的基础设施之一，也是重要的 公共产品。政府作为公共产品管理与维护的主体，以整体性治理为理论基础，搭建沟通协调机制、资 源整合机制、信息共享机制、协同监管机制，完善地下管线综合管理体系，对维护城市安全稳定与可 持续发展具有重要意义。

关键词: 整体性治理 地下管线 综合管理 信息共享 


\section{1. 理论沿革及特点}

整体性治理是在政府实践过程当中对公共管理理 论的一种修正，是政府体制改革对全球化信息技术发展 进程的适应与进步。该理论从解决政府内部机构之间以 及与外部相关部门的整体运行为出发点, 以官僚制作为 基础, 致力于解决与实现政府跨界跨行业跨层级类问题 与服务。整体性治理, 在各个国家和地区实践中称呼不 一, 在英国称为 “整体性政府” (Holistic Government) 或 “合作政府”（Joined-up Government），在美国称 为 “协作型政府” (Collaboration Government), 在 加拿大称为 “水平政府” (Horizontal Government), 在加拿大和新西兰则称为 “整体政府” (Whole of Government）。它是针对新公共管理中功能性组织局限 进行批判和反思的产物。

\section{1. 理论沿革}

整体性治理起源于英国的政府改革实践。从 18 世 纪开始, 英国政府在人口数据收集与整理工作中开创了 整体性的理念，采用了整体性的工作规范协调政府各部 门间的关系。此后, 英国政府在福利制度协调、国家预 算等多方面政府工作中进行整体性尝试, 并建立行业内 整体协调机构在统一进行协调工作与问题解决。20世纪 90 年代初, 英国再次启动 “协同性政府” 方面的改革进 程。发布《现代化政府白皮书》, 旨在构建 “整体政府” 的公共服务模式。形成了统一决策、职能整合、组织整 合、文化整合的全面治理体系。随着信息技术发展与普 及, 计算机信息系统开始在现代政府机构中不断扩大应 用，在美国，信息技术进一步促进了政府机构以及与市 场之间的协调效率, 使得 “联合政府” 跨越不同政府层 次、公众与其他部门进行交易。至此, 整体性治理开始 展现优越性。

\section{2. 理论特点}

整体性治理是顺应全球政府改革浪潮而产生的, 以 问题解决为核心, 提供无缝服务的理论。它植根于政府 改革的发展需求, 并满足多元市场主体的管理需要, 充 分发挥信息技术的优势, 具有以下特点。

\section{2. 1. 着眼于解决政府与各类社会组织的跨 界合作问题}

随着服务性政府理念的建立，市场经济的成熟发展 以及进入全球化市场的程度加深，社会企业与个体对公 共服务提出的要求更加多元化, 要求公共服务反馈的时 效与质量。从英国政府改革实践经验看到, 整体性治理 理论着眼于解决政府组织部门之间的功能整合问题, 以
政府横向的部门结构和纵向的层级结构整合起来，同时 针对外部组织协作强调公私合作，共同以协调问题解决 为核心解决碎片化问题。

\subsection{2. 以现有的官僚制组织结构与运作为基 础}

整体性治理并不是一套固定不变的管理模式套用, 而是通过合作共赢的思想, 因地制宜, 针对性解决地方 性问题。为了解决地下管线的综合管理问题，必须从地 下管线的实际现状与问题出发，以现有的组织结构与制 度框架为基础，改善行政部门之间的信息不畅、落实不 力等问题。

\section{2. 3. 强调信息技术的应用为服务手段}

信息技术是有效的解决问题的手段，公共管理领域 内的分析方法大多植根于社会学研究领域的范畴。随着 全社会信息化应用程度的提高, 管理复杂性越来越高, 信息技术是有效解决复杂性管理问题的手段。

\section{2. 整体性治理视角下地下管线综合管理经验 剖析}

\section{1. 国际经验}

在公共事业方面，美国、英国等发达国家在规划编 制、建设实施、监督管理等环节起步较早，有较多的理 论和实践经验，建立了适合国情的综合管理机制并在实 践中不断更新改进，形成了各自的管理特点。美国城市 总体规划中，公用设施规划是强制要求内容。在监督管 理中强调政府组织与非政府组织之间的协作，除了有规 划规范执行部门之外, 还有管线及危险材料安全管理委 员会（隶属于美国交通部）、共同土地联盟和一呼通中 心，建立 811 专线鼓励民众对地下管线建设管理进行监 督。至此形成了以规划委员会和议会的立法监督和司法 监督为主、民众监督相结合的地下管线综合治理模式。

英国在国家社会服务、健康服务、医疗服务等其他 公共服务管理实践中普遍运用整体性治理理论。英国新 工党认为政府在组织之间的缝隙和接口处最有可能成 功, 它的作用就是粘合剂, 把不同的组织力量 (包括各种 类型的组织、团体、个人、社区等) 团结在一起，让它们 共同发挥作用，这其实就是 “协同政府” 的核心思想。 英国还将管线管理提升到国家管理级别。在 2011 年英 国政府出台《管道法》将管线管理提高到了立法及国家 管理的层级。

由此观之, 市场经济的发展必然会推动公民参与意 识的决心，尤其伴随着城镇化的发展，公民对于城市安 全的关注度越来越高, 市场经济体制不断完善与优化, 
越来越多的非政府组织参与到地下管线的规划建设与 管理中来。英美国家整体性治理模式的特点在于开端在 “规划”、健全综合性的专门化管理机构、发挥非政府 组织机构的作用以及信息技术强有力的支撑。

\section{2. 国内现状}

\section{2. 1. 管理职能}

目前我国地下管线管理工作按照管理主体、对象、 管理阶段等要素进行划分, 主要分为专项管理、行业管 理、权属管理、属地管理以及综合管理。

综合管理职能是指涉及两类以上管线或管线系统 与外部自然和认为环境条件相关问题解决为目标 (包括 当前或未来可能遇到的各类问题) 而开展的一系列管理 活动。

专项管理是指各类管线相关行政部门按照各自职 责对地下管线的规划、建设、管理进行审核、批复、许 可等管理工作。

行业管理主要涉及电力、通信、供排水、燃气、热 力、能源、工信等部门, 主要是推动行业管理工作、解 决行业内产生的问题, 从而对本行业的地下管线实施监 督管理工作。

权属管理是管线权属单位依据法律法规的相关规 定, 履行主体责任对本单位所属的地下管线实施管理与 维护。

属地管线是省、县、乡三级人民政府对地域范围内 的地下管线进行管理和监督工作, 与专项管理、综合管 理、行业管理和权属管理存在交叉。

\section{2. 2. 机构设置}

国家层面涉及部门包括国家发改委、住房城乡建设 部、工信部、广电总局、财政部、国家能源公司等。其 中国家发展改革委员会负责国家重大管线工程的投资 建设管理工作; 国家财政部负责管线工程建设资金管理 工作；国家工业与信息化部负责通讯以及各种工业管线 的规划建设和监督管理工作; 住房城乡建设部负责指导 城市公用设施的规划建设和监督管理工作; 国家广播电 视总局负责有线电视管线的规划建设和监督管理工作; 国家能源局负责能源管线的规划建设和监督管理工作。

由于各地机构设置不同, 地方层面的管线管理部门 设置更加复杂。一般情况下, 发改、财政、规划、城建、 园林绿化、档案等部门分别承担着地下管线投资许可审 批、资金管理、道路审批与规划验收、占掘路审批等职 能。部分城市建立起了比较完备的综合协调管理机构或 成立了综合协调工作小组, 专门负责城市地下管线的综 合协调管理工作。综合协调管理机构以问题为导向, 重 点解决智能管理、行业管理、属地管理、权属管理过程 中存在的跨领域、跨行业、跨层级的协调问题, 从而进
一步为地下管线安全防护、隐患排查、更新改造等工作 提供支持。如北京市城市管理委员会市政管线管理处、 山东省淄博市城建档案和地下管线管理处。

\section{2. 3. 典型经验}

杭州以管理条例为依据, 以全生命周期为核心思想, 对管线的规划、建设、管理、基础信息管理作出全面的 规范。2009 年，杭州市就出台了《杭州市城市地下管线 建设管理条例》，对地下管线工程的施工前、施工中和 竣工后等各个环节的工作进行了比较全面的规范, 并对 基础数据管理提出了具体要求。在属地管理方面, 于 2018 年出台全省首个小城镇环境综合整治地下管线建 档管理工作指导意见。形成了全生命周期的综合管理制 度。

北京市以问题为导向，以解决地下管线安全隐患、 预防管线安全事故为目标，对综合管理体制建设框架进 行顶层设计, 就管线管理对各部门进行科学分工, 建立 了 “综合协调管理、行业和属地监管、权属主体履责” 的管理体制和责任体系。形成了以北京市城市管理委员 会负责综合协调、行业主管部门负责行业监管、各区县 政府管理部门负责属地监管、地下管线权属单位履行主 体管理职责的地下管线运行管理组织体系。为进一步保 证全市管线稳定运行, 建立了信息数据管理体系、隐患 排查治理管理体系、挖掘工程地下管线安全防护机制、 井盖设施协调管理体系等工作机制。形成了侧重运行管 理的综合管理模式。

随着社区共治管理模式的产生与落实，地下管线的 基层管理也试图寻找一种共建共享的管理模式, 进一步 融合专业管理、行业管理、属地管理。在地下管线安全 运行方面, 目前多以开展地下管线保护工作为主。如山 东省青岛市平度市于 2014 年出台《关于加强地下管线 设施保护的意见》（平城建字 [2014]49 号），规定了街 道、镇、园区的地下管线安全保护职责。上海市浦东新 区建立了地下管线管理工作体系，印发了《关于成立浦 东新区地下管线管理工作联席会议的通知》明确了区级 各行政机构职责分工, 落实了地下管线运行单位主体责 任。

\section{3. 存在问题}

\section{3. 1. 缺乏全国性法律法规的统筹}

大多数国内城市均根据实践工作对本地地下管线 管理建设建立了相关管理办法与规范，国家层面目前尚 未出台规范地下管线综合管理方面的法律法规，难以规 范不同行业地下管线权属单位的建设管理行为。因此在 界定国土、住建、能源等不同职能部门在管线管理方面 的职、权、责存在交叉或空白。再加上地下管线大多为 跨区域、跨行业的线性设施，因此在进行整体性管理过 
程中对管理、信息、人员等资源统筹存在不力。

\section{3. 2. 管理职责不清，缺乏有效协调沟通}

地下管线综合管理工作涉及地下管线专项管理部 门、行业管理部门、属地管理部门等, 管理内容繁杂, 导致协调各部门的难度较大, 由于我国行政管理体制 “条块结合” 的特点, 由于职责界定不清, 在管理工作 落地过程中，存在个别管理空白、职责不细致、落实不 到位、缺乏监督等问题。再加上沟通机制不畅, 综合管 理机构解决问题力量有效。

\section{3. 3. 信息化技术共享与利用程度有限}

在信息化建设过程中, 缺乏科学的统筹规划和有效 的制度保障, 还没有一套地下管线管理信息化建设发展 蓝图, 信息化发展整体框架体系未搭建, 一方面导致很 多系统建设完成后成了摆设, 没有发挥重要作用; 另一 方面导致各政府管理部门、行业、企业信息化建设过程 中存在信息壁垒, 现有各信息化平台或信息化功能模块 之间数据存在差异, 数据传输格式不同, 接口协议不同, 难以实现互联互通。

\section{3. 整体性治理下地下管线综合管理体系建设}

从整体性治理视角出发, 以公众需求为导向, 以“协 调、合作、整合、共享”为管理核心，以组织管理体系、 沟通协调机制、协同监管机制、资源整合机制、信息共 享机制建设为主要内容, 以地下管线综合信息管理平台 为支撑, 构建整体性的地下管线综合管理模式, 如图 1。

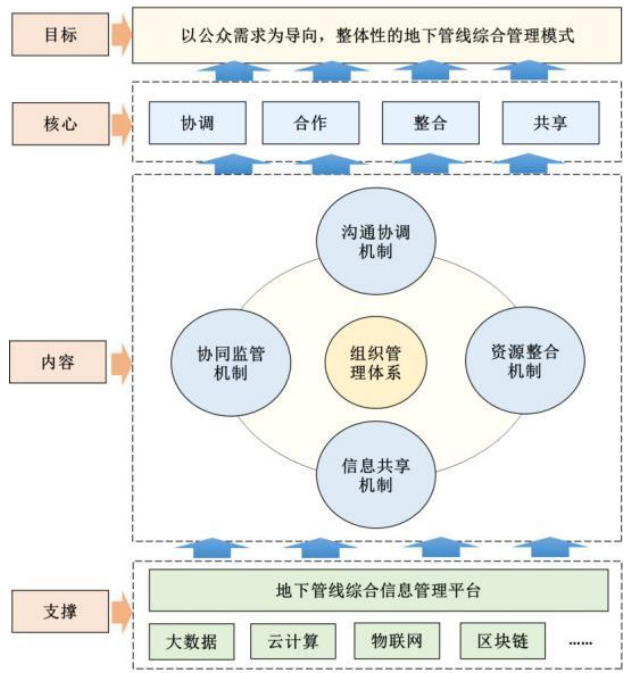

图 1 地下管线综合管理体系框架

\section{1. 沟通协调机制}

地下管线管理主体众多、管理类型复杂等特点决定 了地下管线的综合管理离不开各管理主体之间的沟通 与协调, 从而使地下管线管理各方具有整体性、相互衔 接的管理目标、策略、制度、技术和方法等。地下管线 沟通协调机制主要包括管线全生命周期各阶段、各行业 之间、各区域之间、管线管理与外部环境之间的沟通与 协调。

行业管理方面, 由于地下管线行业特点明显, 各行 业主管部门主要基于本行业的管理需求开展管理工作。 但在各行业管理工作中, 往往更关注于本行业内部的管 理体系建设, 而难以从整体、全局的角度, 去明确本行 业地下管线管理工作的定位。因此，地下管线各行业之 间容易存在沟通协调不足等问题, 这就需要地下综合协 调部门通过统筹管理, 明确各行业管理工作要求, 综合 协调各行业主管部门, 按照地下管线综合管理体系建设 总体目标和要求, 制定行业管理政策, 总体推进各行业 管理部门开展本行业管理工作, 实现行业管理效能的整 合。

属地管理方面，地下管线分布广泛，且地下管线为 线型工程, 其涉及城市范围的各个行政管辖区域, 因此 地下管线管理必然涉及属地管理, 同时还需要各属地管 理部门之间加强沟通与协调，解决管线跨区域问题的衔 接与配合。各区地下管线管理部门之间应加强管线规划、 建设和运行管理之间的衔接与配合, 特别相邻区域管线 管理工作之间的衔接。

另外，地下管线管理不仅涉及地下管线系统本身， 同时涉及地下管线外部人为因素、自然环境等。所以, 在地下管线管理工作中, 不能仅局限于地下管线系统本 身，同时还应将地下管线管理相关的外部因素所涉及的 部门进行统筹考虑。

\section{2. 资源整合机制}

地下管线资源整合包括地下管线综合管理相关的 人力、物资和信息等资源的整合，通过构建地下管线资 源管理体系, 实现各类资源的有机整合和充分利用, 避 免资源过度冗余, 造成资源利用不足。

人力资源整合主要是对地下管线管理部门、地下管 线单位等的功能进行优化, 合理配置相关管理人员、技 术人员等，提升管线管理的人力资源的利用率。可将区 级及街乡级地下管线监管、执法等部门进行整合，借鉴 北京市 “街乡吹哨、部门报到” 工作机制, 实现地下管 线监管、执法工作的高效化。

物资资源整合主要是对地下管线管理相关的设备 设施等进行科学分配和整合。可结合行业管理、属地管 理需求，构建市级地下管线综合管理资源管理体系，将 行业管理、属地管理涉及的地下管线管理资源进行整合, 包括地下管线信息管理系统、网络传输设备、存储设备、 监测监控设备、检测设备、应急救援装备和物资等。

信息资源整合机制主要是通过信息化技术及管理 
手段, 将各类管理主体涉及的技术、标准、安全、平台 等信息进行整合。地下管线管理信息类型包括地下管线 基础信息、规划信息、建设信息、运行维护信息、更新 改造信息、行政审批信息、应急管理信息等。不同管理 主体所掌握的信息内容和范围有所不同, 可通过信息资 源整合，实现信息资源的优化利用。地下管线信息整合 可以地下管线综合管理信息平台为基础, 通过地下管线 综合平台实现对地下管线规划、建设和运行管理全生命 周期信息的整合, 同时平台通过与行业管理系统、企业 管理系统的联接, 实现对行业管理信息、企业管理信息、 管线基础信息的收集与整合, 最终实现全市地下管线信 息管理统一平台。

\section{3. 信息共享机制}

信息共享是充分发挥地下管线基础信息价值，为地 下管线管理主体提供基础支撑、决策支持的重要途径, 也是地下管线信息化、智能化管理的重要组成内容。地 下管线信息共享主要包括政府管理部门之间、政府与企 业之间、政府与社会公众之间的信息共享。

政府部门之间的信息共享主要是基于整合信息、信 息分析以及各部门管理工作需求, 为各政府部门提供信 息服务。综合协调管理部门可通过综合信息管理平台获 取全市地下管线管理信息, 掌握各行业、各区域地下管 线管理情况, 并可对全市地下管线信息进行统计分析, 支撑全市地下管线综合管理策略; 行业主管部门可以获 取本行业地下管线管理信息, 为本行业地下管线监管提 供基础支撑; 区级管理部门可获取本区地下管线管理信 息, 掌握本区地下管线管理现状, 管理薄弱环节, 从而 制定针对性的治理措施。

政府与管线单位之间的信息共享主要为管线基础 信息、管线运行维护信息、管线监管信息的共享。地下 管线权属单位应根据政府管理部门的管理要求, 共享本 单位的日常巡查信息、监测监控信息、检测信息、维修 养护信息等。政府管理部门可根据地下管线权属单位管 理需求及权限, 共享地下管线监管信息, 如管线审批信 息、周边其他管线信息等。

政府管理部门可通过门户网站、移动 APP 等将公众 需求的非涉密的信息与社会公众共享。社会公众可通过 网站、移动 APP 登录信息平台查询地下管线相关管理信 息, 如管线长度信息、小区域的管线相对位置信息、管 线权属单位信息、历史管线维护信息、管线规划信息、 安全信息等。

\section{4. 协同监管机制}

地下管线协同监管机制涵盖政策协同、业务协同和 资源协同。

政策协同即不同层级的管理政策相互协调、组合, 使地下管线相关的国家法律法规、地方法规、部门规章、 规范性文件等之间的关系协调, 形成政策文件互补形成
合力的政策体系。在具体形式方面，市综合协调管理部 门、行业主管部门、属地管理部门应在国家、地方法规 体系框架下, 细化形成市级综合、行业监管、属地监管 的部门规章和规范性文件。

业务协同即基于相关政府机构和职能的优化，实现 政府功能和业务的整合与协同，建立部门与其他相关联 部门工作之间的协调、合作关系。各政府管理部门业务 不仅要考虑地下管线综合管理总体要求，还要结合相关 其他政府管理部门的业务需求，从而与其他政府管理部 门形成政府行政管理和服务合力。

资源协同即各管理主体根据地下管线综合管理体 系要求, 合理确定本部门或本单位的人力、物资、资金 和信息等资源。遵循资源互补、节约成本、充分利用的 原则，明确各类资源的类型、数量、功能、标准以及与 相关政府管理部门、管线单位资源的关系衔接与功能融 合, 构建层次清晰、功能完备的地下管线管理资源体系, 支撑地下管线综合管理工作的整体性。

\section{4. 结语}

整体性治理在政府改革与信息化时代趋势的环境 中应运而生，在历史沿革过程中着眼于解决跨界问题、 提出协调整合的可操作性政策和运用信息技术的服务 手段, 基于官僚制的基础解决综合管理工作实践中的问 题。整体性治理下的地下管线的综合协调管理围绕 “协 调、合作、整合、共享” 的管理核心，并以多领域的管 理实践经验为借鉴，从沟通协调机制、协同监管机制、 资源整合机制、信息共享机制四方面，完善地下管线综 合管理体系。

\section{项目基金}

基金项目：国家重点研发计划资助（项目 编号：2018YFC0704800）；北京市科学技术研 究院萌芽项目（GS201818）；北京市科学技术 研究院海外人才专项资助项目 (0TP-2018-005)

\section{REFERENCES}

[1] Yi Chengzhi. Cross-border Public Affairs, Regional Cooperation Co-governance and Holistic Governance ,2017,49(11):67-78.

[2] Han Zhaozhu, Zhang Dandan.A Review of the Research on Holistic Governance Theory[J]. Journal of Yanshan University (Philosophy and Social Edition).2017,18(01):39-48.

[3] Zhang Xiaojun, Xu Congcong, Zhao Hu. Practices and Enlightenment of Planning, Construction and Management of Urban Underground Pipelines in the United States, 
Britain, Japan and other Countries[A]. Urban Planning Society of China. Urban Times, Collaborative PlanningProceedings of the 2013 China Urban Planning Annual Conference (05-Engineering Disaster Prevention Planning) [C]. Chinese Urban Planning Society, 2013:9.

[4] Wen Shihong. The Rising of Holistic Governance Model: Theory And Practice of Holistic Governance in UK [J]. THE JOURNAL OF SHANGHAI ADMINISTRATION INSTITUTE,2010,11(02):51-58.

[5] Xie Yahong."Joint-up government":the new stage of the development of the new public management[J].Chinese Public Administration, 2004(05):58-61.

[6] Zeng Weihe :Post-New Public Management Era of Cross- agency Collaboration: A Review of Perri 6's Holistic Government, 《Journal of Social Sciences》2012(5)

[7] Exploration and Practice of the Comprehensive Management System of Underground Pipelines in Beijing $[\mathrm{C}]$. Underground Pipeline Professional Committee of China Urban Planning Association. 2015 China International Underground Pipeline Conference.2015:15-20.

[8] Christopher Pollitt. Joined-up Government: ASurvey[j]. Political Studies Review,2003,1(1):34-49

[9] Patrick Dunleavy. Digital Era Government:IT Corporations, the State and E-Government[M]. Oxford: Oxford University press, 2006. 